\title{
Microfluidic platform with four orthogonal and overlapping gradients for soluble compound screening in regenerative medicine research
}

Citation for published version (APA):

Harink, B., Le Gac, S., Barata, D., van Blitterswijk, C., \& Habibovic, P. (2015). Microfluidic platform with four orthogonal and overlapping gradients for soluble compound screening in regenerative medicine research. Electrophoresis, 36(3), 475-484. https://doi.org/10.1002/elps.201400286

Document status and date:

Published: 01/02/2015

DOI:

10.1002/elps.201400286

Document Version:

Publisher's PDF, also known as Version of record

\section{Document license:}

Taverne

Please check the document version of this publication:

- A submitted manuscript is the version of the article upon submission and before peer-review. There can be important differences between the submitted version and the official published version of record.

People interested in the research are advised to contact the author for the final version of the publication, or visit the DOI to the publisher's website.

- The final author version and the galley proof are versions of the publication after peer review.

- The final published version features the final layout of the paper including the volume, issue and page numbers.

Link to publication

\footnotetext{
General rights rights.

- You may freely distribute the URL identifying the publication in the public portal. please follow below link for the End User Agreement:

www.umlib.nl/taverne-license

Take down policy

If you believe that this document breaches copyright please contact us at:

repository@maastrichtuniversity.nl

providing details and we will investigate your claim.
}

Copyright and moral rights for the publications made accessible in the public portal are retained by the authors and/or other copyright owners and it is a condition of accessing publications that users recognise and abide by the legal requirements associated with these

- Users may download and print one copy of any publication from the public portal for the purpose of private study or research.

- You may not further distribute the material or use it for any profit-making activity or commercial gain

If the publication is distributed under the terms of Article $25 \mathrm{fa}$ of the Dutch Copyright Act, indicated by the "Taverne" license above, 


\section{Björn Harink ${ }^{1}$ \\ Séverine Le Gac ${ }^{2}$ \\ David Barata ${ }^{1}$ \\ Clemens van Blitterswijk ${ }^{1}$ \\ Pamela Habibovic ${ }^{1}$ \\ ${ }^{1}$ Department of Tissue \\ Regeneration, MIRA Institute for \\ Biomedical Technology and \\ Technical Medicine, University \\ of Twente, Enschede, The \\ Netherlands \\ ${ }^{2}$ BIOS, The Lab-on-a-Chip Group \\ MESA+ Institute for \\ Nanotechnology and MIRA \\ Institute for Biomedical \\ Technology and Technical \\ Medicine, University of Twente, \\ Enschede, The Netherlands}

Received June 11, 2014

Revised September 19, 2014

Accepted September 24, 2014
Research Article

\section{Microfluidic platform with four orthogonal and overlapping gradients for soluble compound screening in regenerative medicine research}

\begin{abstract}
We present here a screening method based on a microfluidic platform, which can generate four orthogonal and overlapping concentration gradients of soluble compounds over a monolayer of cells, in combination with automated and in situ image analysis, for use in regenerative medicine research. The device includes a square chamber in which cells are grown, and four independent supply channels along the sides of the chamber, which are connected through an array of small diffusion channels. Compounds flown through the supply channels diffuse through diffusion channels into the chamber to create a gradient over the cell culture area. Further, the chamber is connected to two channels intended for introduction of cells and in situ staining. In this study, the dimensions of the different channels were optimized through finite element modeling to yield stable gradients, and two designs were used with gradients spanning 2.9-2.4 $\mu \mathrm{M}$ and 3.4-2.0 $\mu \mathrm{M}$. Next, overlapping gradients were generated using four rhodamine-derived fluorescent dyes, and imaged using confocal microscopy. Finally, the platform was applied to assess the concentrationdependent response of an osteoblastic cell line exposed to a hypoxia-mimicking molecule phenanthroline, using an in situ fluorescent staining assay in combination with image analysis, applicable to closed microfluidic devices. The on-chip assay yielded results comparable to those observed in conventional culture, where a range of concentrations was tested in independent microwells. In the future, we intend to use this method to complement or replace current research approaches in screening soluble compounds for regenerative medicine, which are often based on one-sample-for-one-experiment principle.
\end{abstract}

\section{Keywords:}

Automated image analysis / Hypoxia / In situ imaging / Orthogonal gradients / Regenerative medicine / Screening

DOI 10.1002/elps.201400286

Additional supporting information may be found in the online version of this article at the publisher's web-site

\section{Introduction}

As a direct consequence of an emergent ageing population, the demand for tissue regenerative strategies is increasing.

Correspondence: Dr. Pamela Habibovic, Instructive Biomaterials Engineering Lab, MERLN Institute for Technology-Inspired Regenerative Medicine, Maastricht University, PO Box 616, 6200 MD Maastricht, The Netherlands

E-mail: p.habibovic@maastrichtuniversity.nl

Fax: +31-43-387-5995

Abbreviations: DAPI, 4',6-diamidino-2-phenylindole; FBS, fetal bovine serum; FEM, finite element modeling; HF, hydrogen fluoride; HIF1, hypoxia-inducible factor 1; SAB, secondary antibody
Although application of autograft material, that is, tissue transplanted from elsewhere in the body of the patient to the defect area, is still considered the gold standard for regeneration of most tissues, this approach is associated with important drawbacks, such as donor site morbidity, loss of tissue quality with ageing, and most importantly, limited availability. Therefore, there is an urgent need for regenerative strategies that do not rely on transplantation of tissue and that are off-the-shelf available in large quantities, and at low cost. Stem cell therapy, cell-based and/or growth factor based tissue-engineered constructs as well as natural and synthetic biomaterials are investigated in this context [1].

Colour Online: See the article online to view Figs. 1-4 in colour. 
Classically, the search for alternative (releasable) compounds or combinations thereof, for regenerative medicine applications, is done by a so-called "candidate approach" [2]. In such an approach, a limited number of compounds is selected based on a rationale and assumptions, followed by a long and costly path from characterization to biological assessment both in vitro and in vivo (animal models). However, this approach may lead to omission of potentially good candidates or late apprehension of poor candidates. Furthermore, such a rational design is limited by the lack of knowledge of complex signaling networks, not taking into account concentration, synergistic or temporal effects. Finally, studies are mainly performed on compounds that already have a known effect $[3,4]$, making this approach conceptually weak. As a consequence, methods are sought for that will accelerate and improve the efficacy of this search by better substantiating the choices made, and eventually replace the conventional "candidate approach" by alternative strategies that allow for increase of throughput.

When attempting to screen concentration-dependent effects of a bioactive compound or combined effects of different compounds, one faces the challenge of vastly increasing numbers of conditions. For example, screening the individual and combined effect of only ten compounds at a single concentration would require testing $1023\left(2^{10}-1\right)$ unique conditions. Including different time points and replicates would increase this number even further. Although modern library screening technologies already allow testing of large numbers of compounds, these normally do not take into account combinations, concentration dependence, and temporal effects. A model in which all these parameters are embedded would not only increase the throughput of screening, but would possibly also enhance in vitro to in vitro data translatability. Microfluidics offers a multitude of possibilities to increase throughput of screening, owing to extensive opportunities for integration, parallelization and miniaturization [5]. Moreover, it allows tailoring of (biological) microenvironments with high fidelity, closely mimicking the in vivo situation [6]. The biological microenvironment is of great importance for the fate of the individual cell, as well as for communication among individual cells in the 3D environment of a tissue or organ [7-10].

One very attractive capability of microfluidic systems is to create and control (multiple) gradients of soluble compounds, which allows testing a range of concentration in a single assay, increasing thereby the overall screening throughput. For example, Atencia et al. successfully created a multigradient system that was used to study migration of bacteria [11]. Furthermore, microfluidics can offer a multitude of solutions for biological read-out and can be highly integrated [5, 12]. Devices have been developed that can offer complete cell culture, biological assay and analysis, such as multiple single-cell gene expression [13], and have shown promising results [14]. However, these are usually complex devices with integrated valves and external control systems, which present many technical challenges.

In the present study, we have developed a screening method based on microfluidics, to investigate over time the concentration-dependent and/or combined effects of small soluble molecules on cells relevant to bone regenerative strategies. The screening is performed in a (multi)gradient microfluidic platform capable of generating four orthogonal and overlapping gradients of soluble molecules over a monolayer of adherent cells, in combination with in situ staining and analysis using automated image analysis. The design of the microfluidic platform was first elaborated by finite element modeling (FEM), and compared to empirical fluorescent gradients, as a predictor of gradient generation. Furthermore, a routine was developed to analyze fluorescent images to retrieve information at the single-cell level in an automated way. Using a standalone chip holder, which also functions as an incubator, we performed live imaging and thereby visualized in situ cell interactions with the gradients of overlapping compounds [15]. As a proof of principle, the screening method was applied to test the effects of phenanthroline, a small hypoxia-mimicking molecule with direct applications in regenerative medicine, on the behavior of an osteoblastic cell line [16].

\section{Materials and methods}

\subsection{Cell culture device}

The core of the platform is a microfluidic chip with a square chamber with $650 \mu \mathrm{m}$ sides and a height of $75 \mu \mathrm{m}$, in which cells are cultured (Fig. 1A). The gradients are generated via diffusion by supplying compounds through four supply channels (75 $\mu \mathrm{m}$ high $\times 160 \mu \mathrm{m}$ wide) surrounding the culture chamber. These supply channels are connected to the culture chamber through arrays of smaller diffusion channels (0.5-1 $\mu \mathrm{m}$ high $\times 2-3 \mu \mathrm{m}$ wide $\times 10 \mu \mathrm{m}$ long, each $4 \mu \mathrm{m}$ apart, Fig. 1 Insets). By flowing different compounds through these four supply channels at equal pressure and flow rate, and due to the high relative resistance between the chamber and supply channels, the compounds enter the chamber primarily by diffusion. Each supply channel acts as a source of one compound as well as a sink for compounds from each of the other supply channels. Therefore, overlapping gradients of the four compounds are generated inside the chamber. The gradient can be tuned by changing the size of the channels connecting the main chamber to the supply channels. Two channels (75 $\mu \mathrm{m}$ high $\times 160 \mu \mathrm{m}$ wide) that directly connect to the chamber are meant for inserting, collecting, and in situ staining of cells.

\subsection{Fabrication}

The chip was fabricated in thin glass substrates $(0.21 \mathrm{~mm}$ D263, Schott, Germany) using a two-step wet-etching process. Masks were designed using CleWin (WieWeb, The Netherlands), and fabricated in-house on $5^{\prime \prime}$ soda-lime glass substrates with chromium masking layer using laser lithography (DWL2000, Heidelberg Instruments, Germany). In the first 


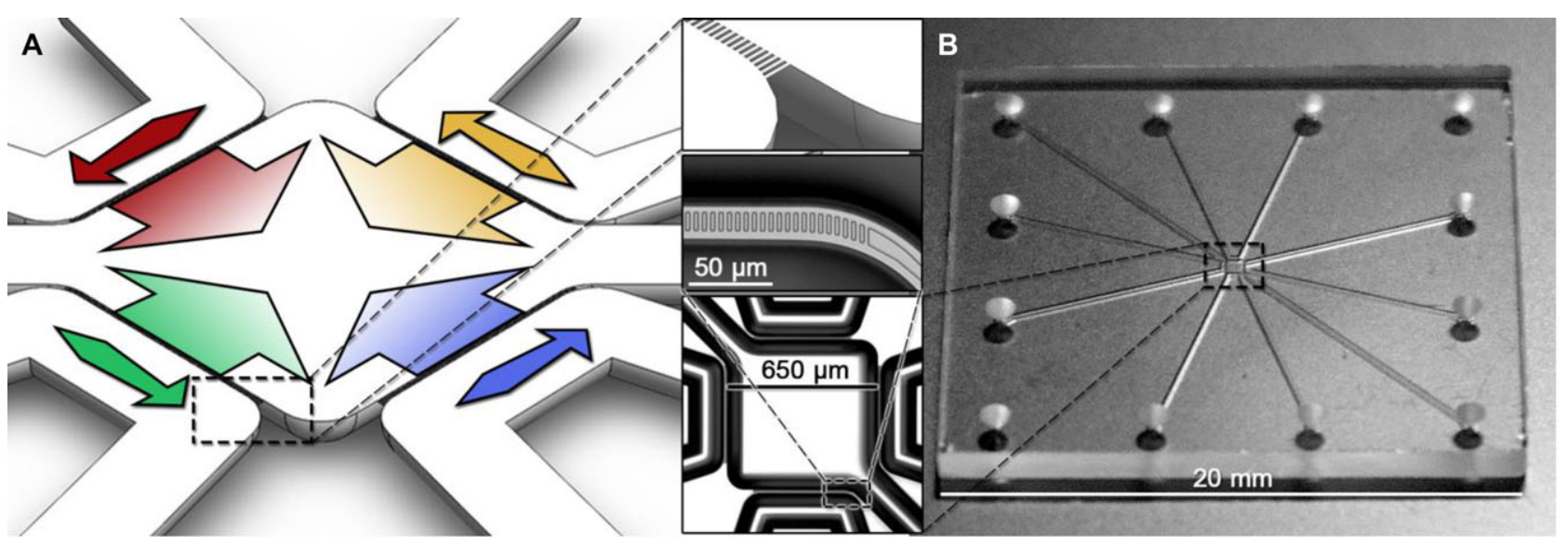

Figure 1. (A) Schematic isometric representation of the four-gradient microfluidic platform, with the four supply channels (75 $\mu \mathrm{m} \times$ $160 \mu \mathrm{m})$ connected to the chamber $(650 \mu \mathrm{m} \times 650 \mu \mathrm{m})$ by channel arrays $(0.5 \mu \mathrm{m} \times 2 \mu \mathrm{m} \times 10 \mu \mathrm{m})$. Arrows in the supply channels depict the direction of the flow, and the arrows inside the chamber depict the direction of the gradients. The top inset shows an enlargement of a channel array. (B) Photograph of the $2 \mathrm{~cm} \times 2 \mathrm{~cm}$ die, depicting the via holes, channels, and chamber in the middle. The middle inset is an enlargement of a fabricated channel array and the bottom inset shows brightfield microscopy image of the fabricated chamber.

etch step, all shallow features with a depth of $0.5-1 \mu \mathrm{m}$ were realized (masking layer: $50 \mathrm{~nm}$ sputtered chromium; etchant: buffered hydrogen fluoride (HF, etch rate of $60 \mathrm{~nm} / \mathrm{min}$; BASF, Germany). An etching time of 16.5 min resulted in a channel depth of approximately $1 \mu \mathrm{m}$, and a width of $3 \mu \mathrm{m}$. In the second step, the chamber and the surrounding supply channels were created, also using standard wet etching (masking layer: $15 \mathrm{~nm}$ sputtered chromium and $200 \mathrm{~nm}$ gold; etchant: $10 \%$ HF (BASF) with an etch rate of approximately $1 \mu \mathrm{m} / \mathrm{min})$. Since HF is not buffered, etch rates are unpredictable and decline in time. Therefore, the etching was performed in several steps and the height of the structures measured after each step using a profilometer (DEKTAK, USA), until a depth of $75 \mu \mathrm{m}$ was reached. In the top glass substrate (1.1 mm D263), via holes were powder blasted, using $29 \mu \mathrm{m}$ alumina particles. Finally, both glass substrates were thermally bonded in an oven $\left(6 \mathrm{~h} \mathrm{ramp} \mathrm{up}, 1 \mathrm{~h}\right.$ at $570^{\circ} \mathrm{C}$, $6 \mathrm{~h} \mathrm{ramp}$ down). After bonding, the wafers were cut in $2 \mathrm{~cm} \times$ $2 \mathrm{~cm}$ dies with a dicing saw (DAD 321, Disco, Japan) followed by polishing (Fig. 1B).

\subsection{Complete setup}

For cell culture experiments, the microfluidic device is inserted in an in-house designed and built standalone chip holder, which provides fluidic connections as well as physiological conditions $\left(37^{\circ} \mathrm{C}, 5 \% \mathrm{CO}_{2}\right.$ supplemented air). Since the glass device is entirely closed, and not gas permeable, gas exchange is provided by gas-permeable perfluoralkoxy inlet tubing $(150 \mu \mathrm{m}$ id and $360 \mu \mathrm{m}$ od paraformaldehyde HP Plus, DuPont, USA) inside the chip holder. The ability to use gas impermeable materials, using this chip holder, keeps the option to study interactions of cells with biomaterials relevant in the field of regenerative medicine, which are generally not gas permeable [15]. The whole platform has the footprint of a microtiter plate and acts as an incubator, allowing the use of a variety of standard equipment for in situ measurement. More details on the standalone chip holder including evidence that, under normal oxygen tension, cells inside the chip are not in a hypoxic state, can be found in previously published work [15].

\subsection{Finite element modeling}

To predict the gradient conditions and aid the design of the gradient platform, FEM was used (COMSOL-MEMS, USA). For the flow, the Navier-Stokes differential was used, with the assumptions of: (i) incompressible flow, since liquids in the applicable pressure range have negligible compressibility; (ii) laminar flow, due to the low flow rates and channel dimensions $(R e \ll 1)$; and (iii) Stokes flow whereby inertial terms can be neglected, resulting in:

$\nabla \cdot\left[p I+\mu\left(\nabla u+(\nabla u)^{\tau}\right)\right]+F=0 \cup \rho \nabla \cdot u=0$,

with pressure $p$, dynamic viscosity $\mu$, velocity vector $u$, the applied force $F$, and density $\rho$. This was then coupled to transport of diluted species, convection, and diffusion, with the assumptions of: (i) neglecting molecular crowding; and (ii) concentration effects, since low concentrations are used with respect to the bulk $\left(c_{i} \ll 1 \mathrm{M}\right)$ :

$\nabla \cdot\left(-D_{i} \nabla_{C_{i}}\right)+u \cdot \nabla_{C_{i}}=R_{i} \cup N_{i}=-D_{i} \nabla_{C_{i}}+u c_{i}$,

with diffusion coefficient $D$, species concentration $c_{\mathrm{i}}$, velocity vector $u$, species source $R_{\mathrm{i}}$, species flux $N_{\mathrm{i}}$, and species number $i$. Models with different dimensions were run to optimize the design. The resulting designs were modeled with different parameters and subsequently compared to the experimental results obtained with fluorescent dyes on the final designs to verify and use the model for gradient prediction. Experimentally, four different fluorescent dyes were used to demonstrate 

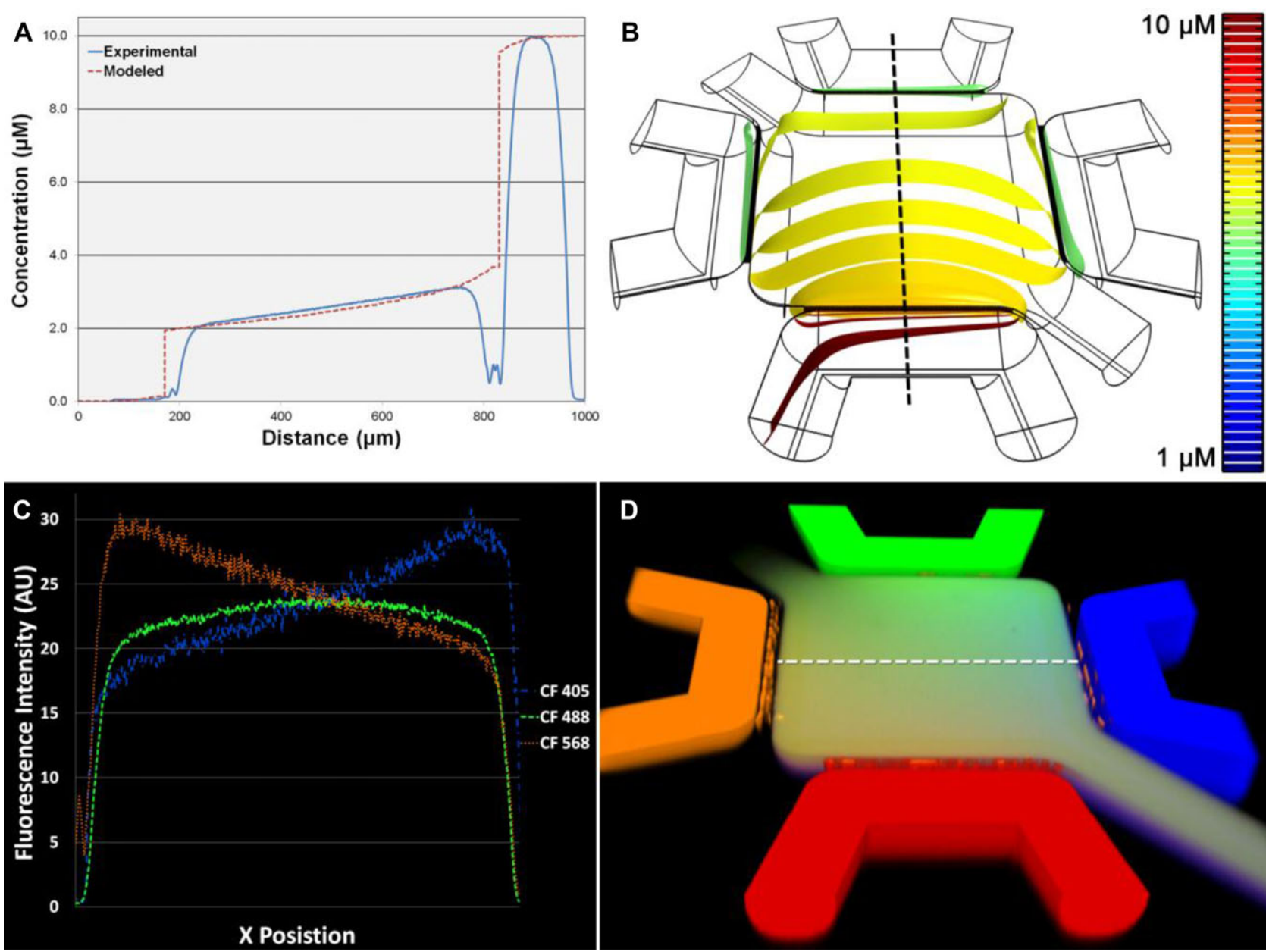

Figure 2. (A) Graph depicting the comparison of an FEM model gradient with a fluorescent experimental gradient, using a chip with $3 \mu \mathrm{m} \times 1 \mu \mathrm{m} \times 10 \mu \mathrm{m}$ diffusion channels. The modeled data (dotted red line) was obtained by finite element analysis and using a parameters for $10 \mu \mathrm{M}$ solution of rhodamine $6 \mathrm{G}$ at a speed of $12 \mu \mathrm{L} / \mathrm{h}$ [17]. The experimental data (solid blue line) were obtained the same conditions, using CE488 fluorescent dye. The line profile was taken from a confocal microscopy image (NIKON Ti-Eclipse with A1 Confocal, Japan), which was taken at a height of $35 \mu \mathrm{m}$ from the bottom of the device (dotted black line in (B)). Since the concentration in the supply channel is known (right peak), and the dye has approximately linear fluorescence emission to concentration in the range of $10 \mu \mathrm{M}$ and below, this peak was normalized to the modeled data. (B) 3D modeled FEM plot of a single gradient starting from the bottom, using the same parameters. Colored lines represent concentration iso-lines. (C) Right to left confocal line scan of the same chamber (horizontal), depicting generated overlapping fluorescent gradients (red, green, and yellow). (D) Confocal 3D volume scan image with all four gradients overlapped.

the ability to simultaneously generate four overlapping gradients. These dyes are derivatives of rhodamine (CF Dyes, Sigma) excited at four different excitation wavelengths (405, 488,543 , and $633 \mathrm{~nm}$ ), specifically selected for the laser lines of the laser scanning confocal microscope (NIKON Ti-Eclipse with A1 Confocal, Japan). All final concentrations were $10 \mu \mathrm{M}$ in DI water (Milli-Q, Millipore), and each solution was flown through one of the supply channels of the chip at a flow rate of $12 \mu \mathrm{L} / \mathrm{h}$. For FEM, the diffusion constant of rhodamine $6 \mathrm{G}$ $(D=400 \mu \mathrm{m} / \mathrm{s})$ was used [17]. Both FEM and experiments with dyes were performed at $37^{\circ} \mathrm{C}$ and $1 \mathrm{~atm}$. The dimensions of the diffusion channels used were $3 \mu \mathrm{m}$ width $\times$ $1 \mu \mathrm{m}$ height $\left(3 \mu \mathrm{m}^{2}\right)$, and a length of $10 \mu \mathrm{m}$. Using confocal microscopy, scans were taken at half-height of the chamber (35 $\mu \mathrm{m})$ and compared to the FEM data at the same flow speed, concentration, and position (Fig. 2). The shape of the gradient was compared by matching the maximum excitation of the known concentration in the confocal scan with the maximum in the model.

\subsection{Cell culture}

Human osteoblast-like MG63 cells were expanded and cultured in alpha minimal essential medium ( $\alpha$ MEM 41061029, Gibco) supplemented with $10 \%$ fetal bovine serum (FBS, Gibco), $100 \mathrm{mg} / \mathrm{mL}$ penicillin, and $100 \mathrm{mg} / \mathrm{mL}$ streptomycin (Pen/Strep, Gibco). To determine the concentration range of interest, and to optimize the imaging analysis, MG-63 cells were first cultured in conventional well plates. Therefore, cells 
were dissociated from the culture flask using 0.05\% trypsin (Trypsin-EDTA, Gibco), seeded in a 96-well microtiter plate at a density of 3000 cells $/ \mathrm{cm}^{2}$, and left to attach and proliferate using normal culture medium. For experiments in the microfluidic device, MG63 cells were dissociated in the same way, and resuspended to a concentration of approximately 5 million cells $/ \mathrm{mL}$. This high concentration of cells was required to ensure sufficient seeding efficiency inside the microfluidic chamber, since due to the dominant surface forces in microfluidics, the cell concentration drops dramatically because the cells tend to concentrate along a single line in the middle of the microchannels. Prior to injection of the cells, the glass chip was cleaned and oxidized using piranha solution (3:1, $100 \% \mathrm{H}_{2} \mathrm{SO}_{4}$ and $30 \% \mathrm{H}_{2} \mathrm{O}_{2}$, Sigma-Aldrich) and subsequently coated with FBS for at least $2 \mathrm{~h}$. The cell suspension was injected into the device via the cell loading channel into the chamber, using a $250 \mu \mathrm{L}$ glass syringe. The final density inside the chamber was approximately $4500 \mathrm{cells} / \mathrm{cm}^{2}$. Thereafter, the inlet and outlet of the chip were closed using shut-off valves to prevent advection during the experiment. The cells were left to attach for $24 \mathrm{~h}$, while flowing cell culture medium through the side channels at a flow rate of $8 \mu \mathrm{L} / \mathrm{h}$, using four $500 \mu \mathrm{L}$ syringes and a single precision syringe pump (Nexus Performance, Chemyx, USA).

\subsubsection{Experiments with phenanthroline, a hypoxia-mimicking small molecule}

To test the cell response to hypoxia in the 96-well microtiter plate, after $48 \mathrm{~h}$ of regular culture, normal cell culture medium was replaced by culture medium supplemented with different concentrations of phenanthroline (1,10-phenanthroline monohydrate, Sigma-Aldrich), ranging from 1.5 to $10 \mu \mathrm{M}$, prepared from a $1 \mathrm{mM}$ solution in methanol (Sigma-Aldrich). The concentration was complemented with a negative, positive $(100 \mu \mathrm{M})$, and secondary antibody (SAB) control, by leaving out the primary antibody. In the on-chip experiments, normal cell culture medium in the syringes was replaced after $24 \mathrm{~h}$ by medium with reduced serum concentration (1\% FBS) for a period of $24 \mathrm{~h}$ to arrest the cell proliferation cycle, with the rationale to improve and equalize response and reduce expression differences among cells, since the number of cells in the chip was much lower than that in the wells of the microtiter plate. After $24 \mathrm{~h}$ in normal and $24 \mathrm{~h}$ in serum-reduced medium, reduced serum medium supplemented with $10 \mu \mathrm{M}$ phenanthroline was added in one syringe to create a gradient from 2.9 to $2.3 \mu \mathrm{M}$ inside the chamber (using a chip with diffusion channels of $2 \mu \mathrm{m}$ width $\times 0.5 \mu \mathrm{m}$ height $\times 10 \mu \mathrm{m}$ length, predicted with FEM modeling: $D_{\text {phenanthroline }}=620 \mu \mathrm{m}^{2} / \mathrm{s}$; $Q=12 \mu \mathrm{L} / \mathrm{h} ; C=10 \mu \mathrm{M})$ [18]. This concentration range was selected for being at the beginning of the slope of the S-curve (shape of a sigmoid function) where concentrationdependent effects of phenanthroline were observed in the experiment in the well plate (Fig. 3D).

\subsubsection{Cell staining and imaging}

After $24 \mathrm{~h}$ of exposure to phenanthroline in either the chip or in the well plate, cell culture was stopped and cells were fixed and stained. On chip, first, the chamber was flushed through the access channels with PBS (Invitrogen), using a syringe, to remove medium. Subsequently, a $4 \%$ paraformaldehyde solution was added for $10 \mathrm{~min}$ to fix the cells, after which the cells were permeabilized with $0.1 \mathrm{w} / \mathrm{v} \%$ Triton-X for $4 \mathrm{~min}$ at $37^{\circ} \mathrm{C}$. Following this, cells were stained with primary antibody Mouse anti-Human Anti-HIF1 $\alpha$ (Abcam) to locate hypoxiainducible factor 1 (HIF1), which stains the alpha subunit of HIF1, for $2 \mathrm{~h}$ at $37^{\circ} \mathrm{C}$; and SAB Goat anti-Mouse IgGAlexa Fluor 488 to stain the located $\mathrm{HIF} 1 \alpha$, for $1 \mathrm{~h}$ at $37^{\circ} \mathrm{C}$. In addition, 4',6-diamidino-2-phenylindole (DAPI, Sigma) counterstain was used to stain the nuclei of the cells. Image acquisition was performed using an automated plate-reading fluorescence microscope (BD Pathway 435, BD Biosciences, USA).

\subsection{Image analysis}

To analyze the results, high-content screening and image recognition was used to locate the nucleus of each cell based on DAPI stain, with high-content imaging software (CellProfiler, Broad Institute, USA). The localized and outlined nuclei were used as overlay on the HIF1 $\alpha$ images (Fig. 3B and C), and the average fluorescent intensity in the nuclei area was measured. The transcription factor HIF1 translocates into the nucleus when the hypoxia pathway is induced. This translocation is visible and measurable as a fluorescence intensity change of the HIF1 $\alpha$ stain in the nucleus. By measuring the mean fluorescent intensity of each individual cell nucleus, the level of translocation was determined for each concentration of phenanthroline. In the case of the on-chip experiments, the nuclei stain was also used for normalizing the fluorescence intensity of the HIF $1 \alpha$ stain to reduce focal plane effects. Graphs and statistics on the resulting data were performed using a statistical software package (SPSS, IBM, USA), and relevant tests were performed as described in Section 3.

\section{Results and discussion}

In this study, we present a method to screen temporal interactions of adherent cells with (eventually multiple) soluble compounds by developing a closed microfluidic platform capable of creating up to four orthogonal and overlapping gradients of compounds in the solution over a cell monolayer. The platform, which is designed for application in regenerative medicine research, is built from glass to allow introduction of relevant biomaterials into the system in the future. The microfluidic platform was inserted into a stand-alone chip holder for cell culture outside the incubator and for timelapse or real-time imaging of cell behavior. FEM was used to aid generation of the desired microenvironment and the 

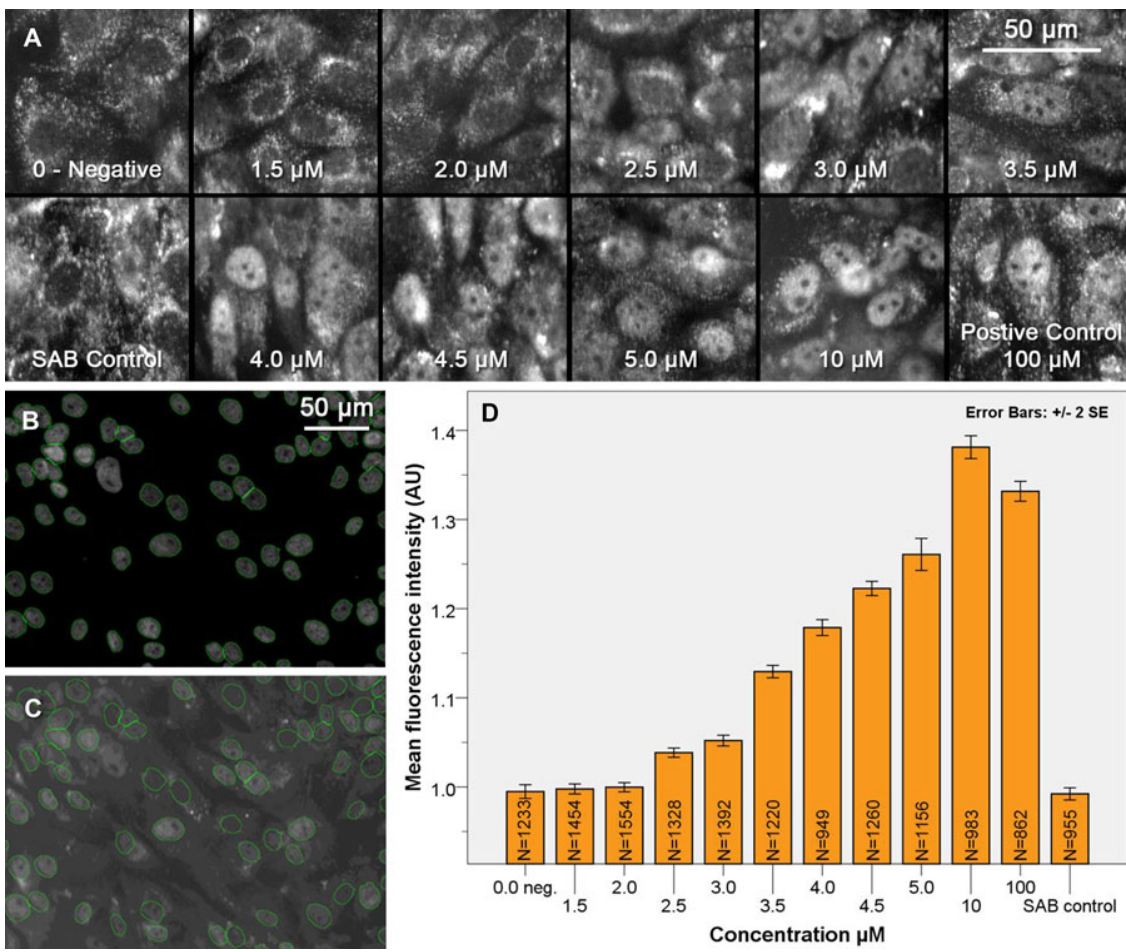
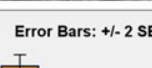
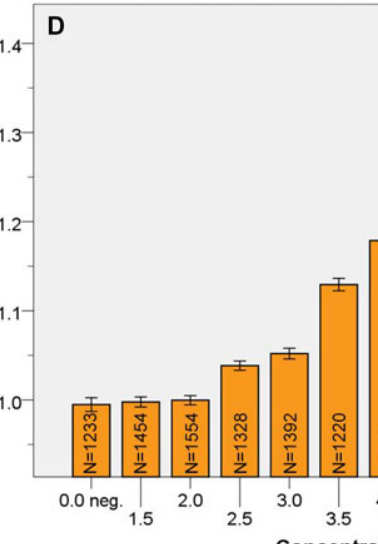

Concentration
Figure 3. (A) Close-ups of fluorescent microscopy images taken from each of the concentration steps from the microtiter plate experiment. (B) Image analysis of cells treated with $10 \mu \mathrm{M}$ phenanthroline, as an example, where the DAPI stain was used to visualize the nuclei, with surrounding lines depicting how the location of nuclei was determined (green). (C) HIF1 $\alpha$ stain image of the same area with the overlay of the located nuclei, allowing for determination of the mean fluorescence intensity of the nuclei, and therefore the level of translocation. (D) Graph depicting the relative fluorescent intensity, normalized to the negative control, in arbitrary units (AU), inside the nuclei of the HIF1 $\alpha$ staining as response to different concentrations of phenanthroline, including negative $(0 \mu \mathrm{M})$, positive $(100 \mu \mathrm{M})$, and secondary antibody (SAB) control. proof of concept was provided by an experiment showing the response of osteoblastic cells to a small molecule that mimics hypoxia.

\subsection{Fabrication}

When designing platforms in which a chemical microenvironment is to be generated with high fidelity, the choice of materials and fabrication methods is of great importance. To ensure stability and prevent deformation, and consequently advection, rigid materials are preferred over elastomeric materials such as PDMS, which is widely used in microfluidics [19]. Elastomeric materials present important limitations in this regard because of their relatively porous nature [20]. Finally, the platform should be amenable to further chemical modification to introduce biomaterials of interest, which, in general, are not gas permeable. The material of choice for the presented platform was therefore glass, which is chemically stable and inert, better characterized in cell culture systems than PDMS, and applicable for high-resolution fabrication [21]. A major issue when using glass, however, is the processing, which is mostly based on wet etching that is associated with low lateral etch control. Dry etching is also possible, however, this is a slow process $(<1 \mu \mathrm{m} / \mathrm{min})$ that requires harsh and complex masking techniques. Furthermore, it requires working with more expensive materials such as quartz or fused silica to ensure the final surface is smooth, which in turn brings about other processing limitations. Therefore, we developed a two-step wet-etching process for common float glass, to produce both shallow nanometer size features $(<1 \mu \mathrm{m})$ and deeper micrometer size features $(>50 \mu \mathrm{m})$, in which we dealt with the adhesion challenges by using better controlled low etch rate solutions (hence, prolonged chemical exposure) for small features.

Conventionally, wet etching of glass uses $\mathrm{HF}$, and a masking layer of $>200 \mathrm{~nm}$ gold, together with a 10-15 nm chromium adhesion layer. For features larger than $10 \mu \mathrm{m}$, this method is usually adequate, but combining features smaller than $10 \mu \mathrm{m}$ with submicron features, as in the platform presented here, required a modified method. First of all, the small-sized diffusion channels possess a very small surface area compared to the end feature size, making adhesion of the masking material to the substrate a challenge. One way to improve adhesion is to reduce the thickness of the gold layer, making it less top-heavy and smaller in comparison to the feature. However, this approach would increase the chance of introducing pinholes caused by imperfections in the sputtering of gold. An alternative is to use a relatively thick chromium layer for masking. Since very "thick" chromium layers introduce stress, the thickness was optimized to $50 \mathrm{~nm}$, as the best balance between adhesion, low-stress and sufficient masking. To control the etch rate, buffered HF was used, rather than HF, resulting in an etch rate of approximately $60 \mathrm{~nm} / \mathrm{min}$.

\subsection{Finite element modeling}

FEM was used for determining the design dimensions, and predicting the gradients to be generated. Generation of more than two overlapping orthogonal gradients is only possible by applying a solely diffusion-based gradient generator [22], and 
not by other approaches such as the flow-based T-cell [23] or mixing-based devices [24]. In the current study, to ensure that diffusion is the dominant force of compound influx into the chamber from the supply channels, three conditions had to be taken into consideration: (i) matching flow conditions in all four supply channels to prevent pressure gradients over the chamber, and therefore advection; (ii) creating high relative resistance between the supply channels and the chamber to minimize the influence of flow disturbances and restrict advection even further; and (iii) low Reynolds number to ensure laminar flow, thus excluding lateral flow.

To match flow conditions in different flow channels as closely as possible, a single high precision pump with multiple syringes was used, ensuring that any remaining pulsatile flow and other disturbances were comparable in all syringes. To achieve high relative resistance, the cell culture chamber was connected to the supply channels through an array of smaller diffusion channels in the submicron range. An approximation of the resistance $\left(R_{\mathrm{h}}\right)$ in a rectangular channel is given by the following formula:

$$
R_{h} \approx \frac{12 \eta L}{w h^{3}\left(1-\frac{0.630 h}{w}\right)} \forall h<w \wedge R e \ll 2000,
$$

given the conditions that the width $(w)$ is larger than the height $(h)$ and the Reynolds (Re) number much lower than 2000. For instance, the resistance in a $50 \mu \mathrm{m} \times$ $100 \mu \mathrm{m} \times 1 \mathrm{~mm}$ channel is approximately $1.4 \times 10^{6} \mathrm{~Pa} \cdot \mathrm{s} \cdot \mathrm{m}^{-3}$ per micrometer and in a $0.5 \mu \mathrm{m} \times 1 \mu \mathrm{m} \times 1 \mathrm{~mm}$ channel is approximately $1.4 \times 10^{14} \mathrm{~Pa} \cdot \mathrm{s} \cdot \mathrm{m}^{-3}$ per micrometer, using a dynamic viscosity $(\eta)$ of $1.0 \mathrm{mPa} \cdot \mathrm{s}$ for water, thus an eight order of magnitude difference, which ensures that the bulk of the flow passes through the supply channel and not into the chamber. Furthermore, it was important to reach a compromise between the dimensions of the diffusion channels and the flow stability, which could be affected by mechanical disturbances from the pump or moving of tubing. With larger channels, steeper gradients could be achieved, however, the flow stability was affected/degraded. Analogously, smaller channels improved the flow stability, but they were limited to the generation of shallower gradients. Low Reynolds number can be obtained by using a syringe pump with high-resolution stepper motor, such that stable low flow rates can be achieved, well within the laminar flow range $( \pm 10 \mu \mathrm{L} / \mathrm{h})$.

Although the gradients are generated by diffusion, the diffusion coefficient of the compound in the solution does not have an influence on the final steady state shape of the generated gradient. It does, however, influence the time required to reach the equilibrium, which is approximately 10 min for rhodamine-like molecules (MW 479), as observed by FEM and fluorescent microscopy. Similarly, the initial concentration of the compound does not influence the shape of the gradient either, as long as it is diluted enough with respect to the solvent. The flow rate has a minor impact on the shape, provided that it remains well within the laminar flow regime, and well above the diffusion rate. Therefore, in the design on the platform presented here, the only parameters that had a significant influence on the generated gradients were the cross-section (width $\times$ height) and length of the diffusion channels. Since we have selected and fixed the length of the channels, the only parameter we varied was the area of the channel. With a channel area of $0.9 \mu \mathrm{m}^{2}$ (semispherical channel of $0.5 \mu \mathrm{m} \times 2 \mu \mathrm{m}$ ), a gradient of $2.9-2.3 \mu \mathrm{M}$ (using $10 \mu \mathrm{M}$ solution) was achieved, and increasing the channel area size to $2.6 \mu \mathrm{m}^{2}$ (semispherical channel of $1 \mu \mathrm{m} \times 3 \mu \mathrm{m}$ ) resulted in a steeper gradient of 3.4-2.0 $\mu \mathrm{M}$. Thus, by increasing the area of the channel by $100 \%$, the concentration range, and therefore the steepness, could be increased by ca. $80 \%$.

The FEM model and the experiment with fluorescent dyes, in which the channel size of $1 \mu \mathrm{m} \times 3 \mu \mathrm{m}$ was selected (Fig. 2A), indicated that the modeled gradient overlaps with the experimental fluorescent gradient. Therefore, the model is valid for predicting the generation of the gradient and the concentration of the compound can be correlated to the distance from the source of the gradient. As stated before, this specific device gives a gradient ranging from approximately 3.4 to $2.0 \mu \mathrm{M}$ at a flow rate of $12 \mu \mathrm{L} / \mathrm{h}$. Figure $2 \mathrm{C}$ shows a confocal line scan, taken through the middle of the chip, from left to right, at half the height of the chamber (see line, Fig. 2D). Figure 2D shows 3D (z-stack) confocal image depicting four overlapping gradients generated simultaneously. A stability test performed over a period of $24 \mathrm{~h}$, while controlling the temperature within a $\pm 0.05^{\circ} \mathrm{C}$ range (major contributor to diffusion speed change) [15], indicated stable gradients with variations in concentration $<4 \%$ (see Supporting Information).

\subsection{Hypoxia mimicking}

As a first proof of concept to show the applicability of this platform in regenerative medicine research, we have investigated the concentration-dependent effects of phenanthroline, a compound previously shown to positively affect angiogenesis, i.e. new blood vessel formation [16], a process that is of great relevance for regeneration of most tissues and organs. In the present study, the effect of this compound was tested on MG63 osteoblastic cell line in the microfluidic gradient platform, and compared to the conventional cell culture conditions. Vascularization is of crucial importance in bone regenerative strategies, in particular for treatment of large bone defects [25]. Phenanthroline is a small molecule from the LOPAC library (Sigma) that was proposed as a relatively inexpensive and stable alternative to growth factors such as vascular endothelial growth factor (VEGF), in stimulating angiogenesis. Phenanthroline has been shown to induce HIF1 expression in a dose-dependent manner. HIF1 is a transcription factor expressed by mammalian cells when they are in a hypoxic (low oxygen) state. It plays an essential role in the systemic response to hypoxia and the release of angiogenic factors, including VEGF [26]. When hypoxia is induced in mammalian cells, HIF1 translocates from the cytoplasm to the nucleus (see Supporting Information for an example), which can be visualized by HIF1 immunostaining. For 

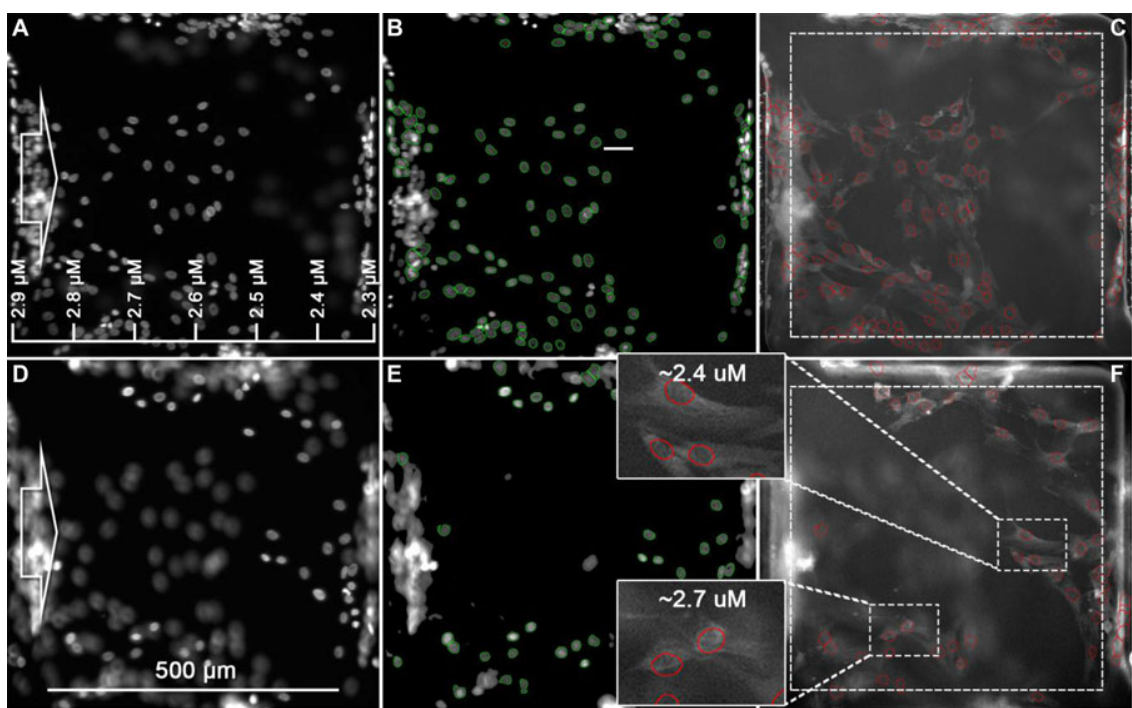

Figure 4. DAPI and $\mathrm{HIF}_{1} \alpha$ stain images and analysis in the microfluidic device after $24 \mathrm{~h}$ of exposure to a phenanthroline gradient of 2.9-2.3 $\mu \mathrm{M}$ (the arrows depict the direction of gradient. (A-C) top and (D-F) bottom of the chamber. (F) Insets show zoom in at different concentrations, where differences in intensity were measured.

the present screen, we have used HIF1 $\alpha$ immunostaining, a subunit of HIF1, followed by quantification of the level of translocation in each cell, by employing high-content screening based on imaging algorithms and demonstrated that this can be a powerful in situ assay, which can be used in closed microfluidic systems, in which generally, a limited number of cells is used.

\subsubsection{Concentration-dependent effects of phenanthroline on MG63 cells in conventional tissue culture}

MG63 cells cultured in 96-well plate were treated with phenanthroline in concentrations ranging from 1.5 to $10 \mu \mathrm{M}$ for $24 \mathrm{~h}$, in duplicates. A $3 \times 3$ montage fluorescent image was taken at $200 \times$ magnification for each condition. Figure 3A displays a zoom in of these images. By plotting the mean fluorescence intensity of the nuclei over the concentration, a concentration-dependent effect was observed in the 2.5-10 $\mu \mathrm{M}$ range (Fig. 3D). All tested concentrations in the $2.5-100 \mu \mathrm{M}$ range differed significantly from each other and the rest $(p<0.05)$. Only the experiments at $0,1.5$, and $2.0 \mu \mathrm{M}$ and the SAB control did not show statistically different levels of translocation. These results translate in a dosedependent S-curve response to phenanthroline in the range of $2.5-10 \mu \mathrm{M}$. At concentrations of $100 \mu \mathrm{M}$ and higher, the compound becomes cytotoxic and more cell death was observed (Fig. 3D), which could explain the reduction in average fluorescence intensity in the nuclei.

\subsubsection{Effect of a microfluidic gradient of phenanthroline on MG63 cells}

Following the proof-of-principle experiments in microtiter plates, a phenanthroline gradient was generated in the microfluidic platform, using the steep part of the S-curve in the dose response of phenanthroline. Accordingly, the chip with diffusion channels of $0.5 \mu \mathrm{m} \times 1 \mu \mathrm{m}$ was used. After $24 \mathrm{~h}$ exposure of MG63 cells to a phenanthroline gradient (2.9-2.3 $\mu \mathrm{M}$, from left to right, Fig. 4), the culture was stopped, and DAPI and HIF1 $\alpha$ staining was performed. We observed that cells attached to both the bottom and the top of the chip, which is probably due to the fact that in a 3D microfluidic environment, cells experience more forces from the walls, while the effect of gravity is negligible. Furthermore, such a confined environment is more favorable for the formation of multilayers than it is the case in a well plate. For this reason, images were taken from both the bottom and top of the chamber. Furthermore, to avoid imaging difficulties, only nonoverlapping cells were selected for the analysis, making the number of cells selected for the analysis lower than the total number of cells in the chip. Figure 4 shows the resulting images after staining of cells upon exposure to the microfluidic gradient-Fig. 4A-C, the top and Fig. 4D-F, the bottom of the chip. By applying a threshold of the intensity of the nucleus stain (Fig. 4A and D), the nuclei out of the focal plane of that layer were discarded, resulting in only located nuclei in focus (Fig. 4B and E). Further selection discarded the nuclei that were in a too close proximity to one another, out of focus, too large, too small, or on the edge of the image.

From the image analysis, the remaining mean intensity values of the HIF $1 \alpha$ stain in each cell nucleus were measured. This intensity was normalized for the nucleus stain intensity to correct for focal differences between cells. All values $50 \mu \mathrm{m}$ from the rim of the chamber (see dotted line Fig. 4C and F) were used for further analysis, and outliers were removed ( $2.5 \times \mathrm{SD}$, five values removed), leaving $N=119$ cells. The values were then placed in a scatter plot for visualization (Fig. 5). Statistical analysis of these data showed that increasing distance from the gradient source, thus decreasing concentration of phenanthroline, had a moderate negative two-tailed correlation $(r=-0.237, p<0.01)$ with normalized HIF1 $\alpha$ fluorescent stain intensity, and linear regression (thick line $=$ regression line, dotted line $=95 \%$ confidence interval, 


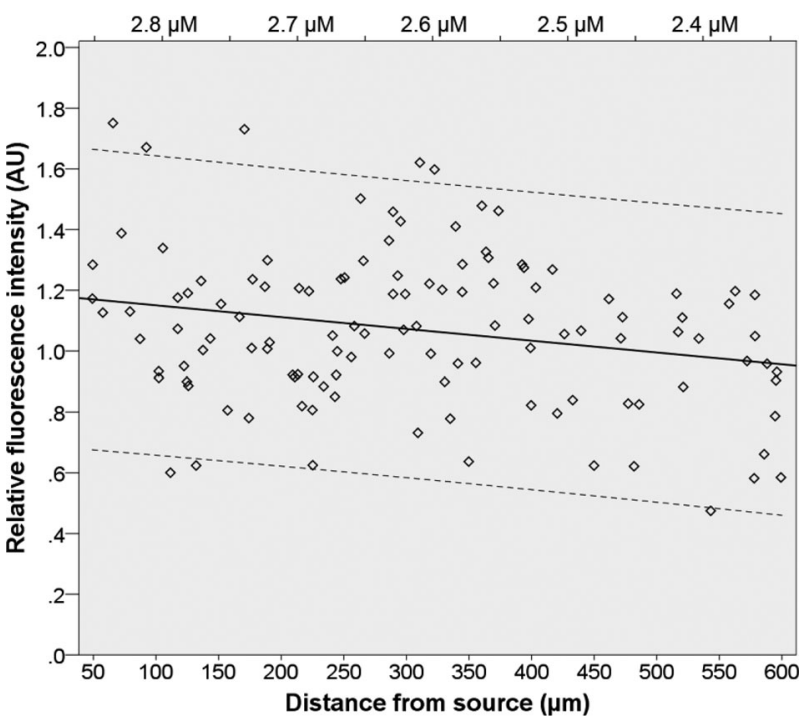

Figure 5. Scatter plot depicting the DAPI stain compensated mean fluorescence intensity of $\mathrm{HIF} 1 \alpha$ stain in the nucleus of each cell, related to the distance from the gradient source. The thick line is the regression line with a moderate negative correlation $(r=-0.237, p<0.01)$ and significant negative relationship $\left(N=119, R^{2}=0.056, F(1,117)=6.957\right.$, $p<0.01$ ). The dotted line depicts the $95 \%$ confidence interval.

Fig. 5 demonstrated a significant negative relationship $\left(R^{2}=\right.$ $0.056, F(1,117)=6.957, p<0.01))$. Although the number of cells is low compared to the conventional culture, and each cell is an experiment instead of treating the whole culture as an experiment, these results indicated that differences in response could be detected in a relatively shallow diffusive gradient of 2.9-2.3 $\mathrm{MM}$ in the microfluidic chip.

\section{Concluding remarks}

In the current study, we have undertaken a first step toward screening of soluble compounds in a concentrationdependent manner for the field of regenerative medicine, by developing a platform that allows testing of up to four independent soluble species in a single experiment. While in this first step, we have provided the proof of concept of our device by testing the biological effect of one compound only, we have validated the possibility to simultaneously generate four identical but orthogonal gradients in a single device, using fluorescent dyes. In the presented device, the gradient was relatively shallow, which precludes the study of compounds in which subtle concentration differences are effective, and which obviously still limits the analysis throughput if a large range of concentrations needs to be assessed. We are currently working on a second-generation device, exhibiting a wider concentration gradient. Nevertheless, a serial dilution approach or comparable systems may be more appropriate for initial screenings before a gradient-based platform as presented here is used to study any combined effects of various compounds. On other aspects, the number of cells in one cell culture chamber was too small in the presented experiments to yield enough statistically relevant data, and this issue will become even more critical when more than one compound is simultaneously tested, whereby very few cells will be exposed to a unique combination. In the future, this limitation can be addressed by using several identical chambers in parallel, which are run under the same experimental conditions. Finally, another aspect requiring additional attention in the future is the possible existence of "side effects" of having a gradient over a monolayer of cells, such as polarization, chemotaxis, or directional growth of cells. In addition to the microfluidic platform, this study was also aimed at developing an accompanying in situ image analysis method that allows time-lapse or real-time imaging of cell behavior upon exposure to soluble compounds. In an initial experiment conducted in a microtiter plate format, a routine was developed based on image analysis of nuclei and HIF1 $\alpha$ staining to study concentration-dependent responses of mammalian cells to phenanthroline exposure. In a subsequent experiment, a comparable image analysis was performed in the microfluidic platform where a shallow gradient of phenanthroline was created, enabling testing of a given range of concentration in a single experiment. This second experiment demonstrated that the proposed method can also be used to detect dose-response differences inside a shallow diffusive gradient, while retaining the spatial information.

Pamela Habibovic acknowledges financial support by Innovative Research Incentives Scheme Veni no. 10236 of the Netherlands Organization for Scientific Research (NWO).

The authors have declared no conflict of interest.

\section{References}

[1] Yang, L., Harink, B., Habibovic, P., in: Ducheyne, P. (Ed.), Comprehensive Biomaterials. Vol. 1, Elsevier, Oxford 2011, pp. 299-312.

[2] Danoux, C. B. S. S., Tare, R., Smith, J. O., Bradley, M., Hunt, J. A., Oreffo, R. O. C., Habibovic, P., in: Boer de, J., Blitterswijk van, C. A. (Eds.), MateriomicsHigh-Throughput Screening of Biomaterial Properties, Cambridge University Press, Cambridge, UK 2013, pp. 155-175.

[3] Held, M. A., Langdon, C. G., Platt, J. T., Graham-Steed, T., Liu, Z., Chakraborty, A., Bacchiocchi, A., Koo, A., Haskins, J. W., Bosenberg, M. W., Stern, D. F., Cancer Discov. 2012, 3, 1-16.

[4] Borisy, A. A., Elliott, P. J., Hurst, N. W., Lee, M. S., Lehar, J., Price, E. R., Serbedzija, G., Zimmermann, G. R., Foley, M. A., Stockwell, B. R., Keith, C. T., Proc. Natl. Acad. Sci. USA 2003, 100, 7977-7982.

[5] Thorsen, T., Maerkl, S. J., Quake, S. R., Science 2002, 298, 580-584.

[6] Young, E. W. K., Beebe, D. J., Chem. Soc. Rev. 2010, 39, 1036-1048.

[7] Park, J. Y., Takayama, S., Lee, S.-H., Integr. Biol. 2010, 2, 229-240. 
[8] Gilbert, P. M., Havenstrite, K. L., Magnusson, K. E. G., Sacco, A., Leonardi, N. A., Kraft, P., Nguyen, N. K., Thrun, S., Lutolf, M. P., Blau, H. M., Science 2010, 329, 1078-1081.

[9] Burdick, J. A., Vunjak-Novakovic, G., Tissue Eng. Part A 2009, 15, 205-219.

[10] Harink, B., Le Gac, S., Truckenmüller, R., van Blitterswijk, C., Habibovic, P., Lab Chip 2013, 13, 3512-3528.

[11] Atencia, J., Morrow, J., Locascio, L. E., Lab Chip 2009, 9, 2707-2714.

[12] Maerkl, S. J., Integr. Biol. 2009, 1, 19-29.

[13] Gong, Y., Ogunniyi, A. O., Love, J. C., Lab Chip 2010, 10 , 2334-2337.

[14] Dalerba, P., Kalisky, T., Sahoo, D., Rajendran, P. S., Rothenberg, M. E., Leyrat, A. A., Sim, S., Okamoto, J., Johnston, D. M., Qian, D., Zabala, M., Bueno, J., Neff, N. F., Wang, J., Shelton, A. A., Visser, B., Hisamori, S., Shimono, Y., van de Wetering, M., Clevers, H., Clarke, M. F., Quake, S. R., Nat. Biotechnol. 2011, 29, 1120-1127.

[15] Harink, B., Le Gac, S., Barata, D., van Blitterswijk, C. Habibovic, P., Lab Chip 2014, 14, 1816-1820.
[16] Doorn, J., Fernandes, H. A. M., Le, B. Q., van de Peppel, J., van Leeuwen, J. P. T. M., De Vries, M. R., Aref, Z., Quax, P. H. A., Myklebost, O., Saris, D. B. F., van Blitterswijk, C. A., de Boer, J., Biomaterials 2013, 34, 3053-3063.

[17] Gendron, P.-O., Avaltroni, F., Wilkinson, K. J., J. Fluoresc. 2008, 18, 1093-1101.

[18] Li, S., Mottola, H. A., Anal. Chim. Acta 1994, 289, 79-85.

[19] Duffy, D. C., McDonald, J. C., Schueller, O. J., Whitesides, G. M., Anal. Chem. 1998, 70, 4974-4984.

[20] Toepke, M. W., Beebe, D. J., Lab Chip 2006, 6, 1484-1486.

[21] Mukhopadhyay, R., Anal. Chem. 2007, 79, 3248-3253.

[22] Keenan, T. M., Folch, A., Lab Chip 2008, 8, 34-57.

[23] Lin, F., Butcher, E. C., Lab Chip 2006, 6, 1462-1469.

[24] Li Jeon, N., Baskaran, H., Dertinger, S. K. W., Whitesides, G. M., Van de Water, L., Toner, M., Nat. Biotechnol. 2002, 20, 826-830.

[25] Krishnan, L., Willett, N., Guldberg, R., Ann. Biomed. Eng. 2014, 42, 432-444.

[26] Wang, G. L., Jiang, B. H., Rue, E. A., Semenza, G. L., Proc. Natl. Acad. Sci. USA 1995, 92, 5510-5514. 